Publisher: Taylor \& Francis

Journal: Ergonomics

DOI: http://dx.doi.org/10.1080/00140139.2016.1188218

\title{
Automotive HMI design and participatory user involvement: Review
} and perspectives

Mathilde François ${ }^{1,2}$, François Osiurak ${ }^{1,3}$, Alexandra Fort ${ }^{4}$, Philippe

Crave $^{2}$, Jordan Navarro ${ }^{1}$

${ }^{1}$ Laboratoire d'Etude des Mécanismes Cognitifs, Université de Lyon, Bron, France

${ }^{2}$ Volvo Group Trucks Technology (GTT), Saint Priest, France

${ }^{3}$ Institut Universitaire de France, Paris, France

${ }^{4}$ IFSTTAR-TS2-LESCOT, Bron, France

Corresponding author:

Mathilde FRANCOIS

Renault Trucks - AB VOLVO

API: TER L10 001

99, Route de Lyon

69802 Saint-Priest Cedex, France

Phone: +33 (0)4 81930324

Mobile: +33(0)6 71226371

Email: mathilde.francois@volvo.com 
François Osiurak

Laboratoire d'Etude des Mécanismes Cognitifs (EMC EA 3082)

Institut de Psychologie

Université Lyon 2

5, Avenue Pierre Mendès-France

69676 Bron Cedex, France

Phone: +33 (0)4 78774395

Email: francois.osiurak@univ-lyon2.fr

Alexandra Fort

IFSTTAR-TS2-LESCOT

25, Avenue François Mitterrand

69675 BRON Cedex, France

Phone: +33 (0)4 72142580

Email: alexandra.fort@ifsttar.fr

Philippe Crave

Renault Trucks - AB VOLVO

API: TER L10 001

99, Route de Lyon

69802 Saint-Priest Cedex, France

Phone: +33 (0)4 26830818

Email:philippe.crave@volvo.com

Jordan Navarro

Laboratoire d'Etude des Mécanismes Cognitifs (EMC EA 3082)

Institut de Psychologie

Uniyersité Lyon 2

5, Avenue Pierre Mendès-France

69676 Bron Cedex, France

Phone: +33 (0)4 78774395

Email: jordan.navarro@univ-lyon2.fr 


\section{Acknowledgement}

This work was performed within the framework of the LABEX CORTEX (ANR-11-LABX0042) of University of Lyon, within the program 'Investissements d'Avenir' (ANR-11-IDEX0007) operated by the French National Research Agency (ANR). This work has also been made possible through a CIFRE PhD convention from the ANRT (ANRT-2013/1405), funded by the French Ministry of Higher Education and Research. The authors wish to thank Eric Dutt for having been a source of reflexion and Ghislaine Goullioud for their useful comments on an earlier version of this paper. 


\title{
Automotive HMI design and participatory user involvement: Review and perspectives
}

\begin{abstract}
Automotive human-machine interface (HMI) design is facing new challenges due to the technological advances of the last decades. The design process has to be adapted in order to address human factors and road safety challenges. It is now widely accepted that user involvement in the HMI design process is valuable. However, the current form of user involvement in industry remains at the stages of concept assessment and usability tests. Moreover, the literature in other fields (e.g. information systems) promotes a broader user involvement with participatory design (i.e. the user is fully involved in the development process). This article reviews the established benefits of participatory design and reveals perspectives for automotive HMI quality improvement in a cognitive ergonomic framework.
\end{abstract}

\section{Keywords}

Human-machine interface, user involvement, user-centred design, participatory design

\section{Practitioner Summary}

Automotive HMI quality determines, in part, drivers' ability to perform primary driving tasks while using in-vehicle devices. User involvement in the design process is a key point to contribute to HMI quality. This article reports the potential benefits of a broad involvement from drivers to meet automotive HMI design challenges. 


\section{Introduction}

For a long time, the design of automotive human-machine interfaces (HMI) was determined by technical constraints and the extent of the features made possible by the technology. Nevertheless, the limited amounts of information that can be handled by the driver and road safety issues have forced a shift in design approach. Human-machine interface design has moved from technology-centred and feature-driven approaches to human-centred design approaches (i.e. applying human factors and usability knowledge). Among human-centred approaches, user-centred design (i.e. considering the users' perspective to achieve a usable system) has become the standard for automotive HMI design. Drivers are involved during usability tests for interface assessment, and it is now widely accepted that user involvement in the HMI development process is valuable (e.g. Bekker and Long 2000; Preece, Rogers, and Sharp 2002).

Another human-centred approach, participatory design, has had great success for more than four decades and has demonstrated clear benefits in other fields (e.g. information systems, physical ergonomics). Participatory design implies a proactive role by the user throughout the process, including concept design activities. Compared to other approaches, participatory design may allow the accessing of users' mental models and preferences, which would improve product quality and user acceptance (Spinuzzi 2005). In the HMI design field, few articles have reported on participatory design (e.g.

Moraes and Padovani 1998; Bilal 2013; Bruno and Muzzupappa 2010), and none of them made a cognitive ergonomic evaluation of the product designed (e.g. measures of efficiency and satisfaction).

Therefore, the question arises: how could automotive HMI design benefit from participatory design compared to user-centred design from a cognitive ergonomic 
perspective? The objective of this article is to provide a comprehensive literature review of the benefits of participatory design and to report on the perspectives to meet automotive HMI challenges.

In the first section, cognitive ergonomic challenges related to automotive HMI design are presented. Then, a review of participatory design benefits is provided in the second section. Lastly, participatory design benefits are linked to automotive HMI challenges to highlight potential research and application perspectives. This article concludes with a discussion on the participatory design approach.

\section{Automotive HMI design}

The quality of the automotive HMI determines, in part, the driver's ability to perform the primary driving task while using in-vehicle devices. Various internal and external factors (Leplat 1981) can influence interaction quality. Internal factors are driver characteristics (e.g. experience level, motivation, age, emotional status, time pressure, etc.). External factors include context characteristics (e.g. level of emergency, task consequences, lighting conditions, etc.) and the characteristics of the interface itself (e.g. ease of use, menus, modality used, colours, voice recognition, etc.). Humanmachine interface designers have a limited impact on driver and context factors. However, by specifying interface characteristics, HMI designers directly impact the way the user interacts with a device and performs the primary task. Cognitive ergonomic criteria are used by HMI designers as design principles as well as assessment factors to generate interfaces compatible with human capabilities and limitations. In this article, we will focus on three fundamental criteria for automotive HMI: usability, distraction, and acceptance. 
These three criteria cover the main measures existing in the literature to define the quality of an interface. Usability is the most used criterion for interface evaluations, but driving safety and user acceptance can have critical implications for automotive HMI due to the specific context of use. The theoretical question of interaction and weight between these three criteria is not addressed in this article. More detailed and specific models on the ergonomic quality of automotive HMI exist in the literature (e.g. Harvey et al. 2011). In this article, the objective is to adopt a holistic and practical framework in order to examine automotive HMI design challenges and meet practitioners' concerns. The proposed framework based on the three criteria (i.e. usability, distraction, and acceptance) is presented in Table 1. In the following parts, each criterion is defined with its scope and the associated design challenges.

-- Insert Table 1 here -

\subsection{Usability}

Nielsen (2012) defined usability as 'a quality attribute that assesses how easy user interfaces are to use'. It is the leading criterion in the cognitive ergonomic literature to define HMI quality. Many models of usability were proposed; Nielsen (1994) summarised with the following five constructs: learnability, efficiency, memorability, errors, and satisfaction (see definition in Table 1). Besides those constructs, many subcriteria of usability have been proposed that are not really consistent across standards. Baber (2005) highlighted this diversity by reviewing 34 different factors of usability. The International Organization for Standardization (1998) considered three aspects: effectiveness (i.e. accuracy and completeness to complete a task), efficiency (i.e. resources expended to complete a task), and satisfaction (i.e. comfort and pleasure of 
usage). Constantine and Lockwood (1999) defined usability as a combination of learnability, system reliability, efficiency, memorability, and user satisfaction. Preece et al. (2002) associated learnability with flexibility, throughput, and attitude. Shackel (1986) identified four usability criteria: learnability, flexibility, effectiveness, and user attitude. Stanton and Baber (1992) added perceived usefulness, task match, task characteristics, and user criteria. Shneiderman (1992) proposed five attributes: time to learn, speed performance, rate of errors, retention over time, and subjective satisfaction. Nevertheless, the different terms often overlap the same characteristics. The model of Nielsen (1994) has the advantage of presenting a global and representative view of the main theories. The learnability criterion was also present in the models of Constantine and Lockwood (1999), Preece et al. (2002), and Shackel (1986), and matches the criterion of time to learn of Schneiderman (1992). Efficiency encompasses the notions of effectiveness (International Organization for Standardization 1998; Shackel 1986), efficiency (International Organization for Standardization 1998; Constantine and Lockwood 1999), throughput (Preece et al. 2002), and speed performance (Schneiderman 1992). The memorability construct has already been presented by Constantine and Lockwood (1999), and matches the concept of retention over time of Schneiderman (1992). The errors criterion embraces the following criteria: system reliability (Constantine and Lockwood 1999), flexibility (Preece et al. 2002; Shackel 1986) and rate of errors (Schneiderman 1992). Finally, satisfaction was already present in definition of usability (International Organization for Standardization 1998;

Constantine and Lockwood 1999), and matches the constructs of attitude (Preece et al. 2002; Shackel 1986) and subjective satisfaction (Schneiderman 1992).

During automotive HMI design, one way to incorporate usability is to follow design principles, i.e. HMI guidelines (JAMA 2004; Stevens et al. 2002; Campbell et al. 
2007; Commission of the European Communities 2005) or usability heuristics (Nielsen 1994; Bastien and Scapin 1992). Likewise, tests can be performed after concept definition to assess HMI usability. Nevertheless, some criteria are easier to assess than others. For example, errors can be measured in terms of type, rate, and ease of recovery, but user satisfaction could comprise any number of different sub-attributes. Moreover, memorability could be more significant for infrequently used vehicle functions (e.g. fog lights) than for those which are used frequently (e.g. indicators).

\subsection{Distraction}

Distraction is defined in the literature as a diversion of attention from the driving task to a concurrent activity (Pettitt, Burnett, and Stevens 2005). Distraction can be related or not to driving and due to an event, object, or person inside or outside the vehicle (Chapon, Gabaude, and Fort 2006). The interaction with automotive HMI can result in distraction related to driving (e.g. following a map on a GPS) or in not related to driving (e.g. changing radio volume). In both cases, the interaction with the HMI could imply physical distraction (e.g. at least one hand off the steering wheel, eyes off the road, etc.) and/or cognitiye distraction (i.e. cognitive workload needed to perform a task; Chapon, Gabaude, and Fort 2006). Distraction can significantly impair the driver's visual search patterns, reaction times, decision-making, and/or driving performance (e.g. position on the road; Young, Regan, and Hammer 2007). Divided attention in itself leads to an increased workload; mental workload management while interacting with in-vehicle devices is therefore crucial to keep resources available for the primary driving task (Young et al. 2015).

The distraction criterion is central in the automotive HMI domain and is, for that reason, treated separately here from usability, even though this concept is clearly linked 
with efficiency. Indeed, in-vehicle HMI is used under a specific context of use. The importance of the dual task interference (Harvey et al. 2011) and its impact on driver distraction distinguish automotive HMI from other user interfaces (Marcus 2004).

During design, many interface characteristics can be considered to reduce distraction. For example, Reimer et al. (2014) stressed that the typeface design in an automotive user interface impacts on task completion time and visual demand while driving (e.g. a difference of more than $10 \%$ of total glance time was found between two typefaces). However, for HMI designers, anticipating sources of distraction during concept design is quite complex. The distraction criterion is most often addressed through assessment with measures such as driving performance during interaction (Young et al. 2007), gaze away from road (e.g. total eyes off-road time, maximum glance duration; Larsson and Niemand 2015), cognitive workload (Stanton et al. 2013), situation awareness (Ma and Kaber 2007), reaction times (Navarro, Mars, and Hoc 2007), etc. Moreover, a guideline has been created to assess driver distraction (National Highway Traffic Safety Administration 2012) with visual-manual distraction metrics and acceptance thresholds (e.g. devices should be designed so that drivers can interact without looking away from the road for more than 2 seconds).

\subsection{Driver acceptance}

Driver acceptance is defined by Adell $(2010,477)$ as 'the degree to which an individual intends to use a system and, when available, to incorporate the system in his/her driving'. Driver acceptance covers user attitudes, their subjective experiences, and their willingness to use technology for the task for which it was intended. Acceptance contributes widely to automotive technology adoption (i.e. the use of a device as part of a driver's everyday life; Najm et al. 2006). Following the rapid development of 
technology, the concept of acceptance and its relation to usage behaviour has become a significant research question. A number of different models have put emphasis on different aspects of user acceptance. Among the many variables that may influence acceptance or rejection of a technology, the technology acceptance model (TAM; Davis, Bagozzi, and Warshaw 1989) - based on the theory of reasoned action (Fishbein and Ajzen 1975) - suggests that perceived usefulness and perceived ease of use impact on user attitudes towards using, determining the behavioural intention to use. More recently, Venkatesh et al. (2003) proposed the unified theory of acceptance and use of technology (UTAUT). This model states that usage behaviour is influenced by intention to use and facilitating conditions. The intention to use is in turn impacted by performance expectancy, effort expectancy, and social influence. Besides those factors, Nielsen (1994) has stressed the importance of utility when describing practical acceptance. Indeed, a system can be usable but not necessarily useful. Van Der Laan, Heino, and De Waard (1997) confirmed this point by identifying usefulness and satisfaction as the two dimensions of acceptance. Willingness to use is also dependent on driver satisfaction, and some subjective criteria are suggested such as aesthetics, emotional appeal, pleasure, fun, coolness, and attractiveness (Preece, Rogers, and Sharp 2002; Baber 2005).

Although subjective attributes are recognised as playing a great role in user acceptance, they are more difficult to translate into specifications during HMI concept design. Furthermore, the concept of acceptance relates to the user's attitude toward a technology, and the HMI only partially contributes to this (e.g. Brown et al. 2015). Driver acceptance is therefore often addressed during concept assessment through questionnaires and subjective reports (e.g. Van Der Laan, Heino, and De Waard 1997). 


\section{User involvement and design processes}

During product development, even if designers are close to users and know product usages, their perceptions and reflections could be modulated by their knowledge. Nielsen (2008) reported that designers know too much about the product, are too skilled in using computers or tools in general, and 'care too much about their own baby'. The ISO 13407 guideline (1999) thus recommends active user involvement to create products compatible with users, tasks, and environment requirements. The humancentred approach aims to take into account the context of use and human factors. According to ISO 9241-210 (2006), the human-centred design process splits into three stages through an iterative process: 1) analysis (understanding context of use and specifying user requirements), 2) concept design, and 3) concept assessment. Humancentred design includes different design methodologies according to their level of user involvement throughout the process. Eason (1995) distinguished three levels of user involvement for product development: a design for users, a design with users, and a design by users. Damodaran (1996) took up those levels by characterising user involvement as being somewhere on the continuum from informative, through consultative, to participative. The correspondence between those three levels of user involvement and the stages of the human-centred design process is presented in Figure 1.

-- Insert Figure 1 here - 


\subsection{User-centred design: A design for and with users}

Human-centred approaches are manifold, e.g. ethnography (Blomberg et al. 1993), the lead user approach (Herstatt and Von Hippel 1992), contextual design (Beyer and Holtzblatt 1999), joint application design (Carmel, Whitaker, and George 1993), and empathic design (Leonard and Rayport 1997). Among human-centred approaches, the user-centred design process has been widely and predominantly used for about 30 years. The main goal is to develop a product while keeping the user in mind and promote usability by detecting and avoiding potential interaction issues before product implementation (Gould and Lewis 1985; Karat 1997). User-centred design plays a significant role in research and practice to consider users' needs and expectations, focus on interaction, and improve communication between designers and users.

User involvement in user-centred design is informative and/or consultative (Bekker and Long 2000). With informative involvement, users are considered as a source of information for the analysis stage, but the design team ensures the concept design and assessment. Information on users is collected using different tools such as surveys (Preece et al. 1994), field studies (Preece et al. 1994), diary keeping (Poulson, Ashby, and Richardson 1996), task analysis (Kirwan and Ainsworth 1992), user requirement interviews (Macaulay 1996), focus groups (Caplan 1990), personas (Olsen 2004), and scenario of use (Nielsen 1990).

With consultative involvement, users provide information during the analysis stage but also take part in the assessment phase. They are requested to give their feedback on concepts designed by the design team (e.g. with usability tests). Dumas and Redish (1993) summarised the main benefits of usability testing: to improve the product's usability, involve real users, give users real tasks to accomplish, enable 
designers to observe and record users' actions, and enable designers to make changes accordingly.

Notwithstanding, some limitations can be reported for user-centred design. The principal criticism is that designers have a controlling approach (Lee 2008). In fact, concepts are created by engineers, and users are only consulted to evaluate them. The implementation of user-centred design in practice often implies an assessment with a limited set of features covered, during a limited time, and, often, with a small number of participants (Abras, Maloney-Krichmar, and Preece 2004). Moreover, user-centred design focuses principally on how the user reacts to a prototype and fails to capture what they could bring to the concept design.

\subsection{Participatory design: From a design for users to a design by users}

Another major human-centred approach, called participatory design (or collaborative design), implies participative user involvement. With participative involvement, users contribute directly and proactively to the concept design phase (Sanders 2002). The user's role is not just confirmatory but continuous from the analysis, throughout the concept design, to the assessment stages. Although user-centred design and participatory design are very close, the active role of the user throughout the process, including concept design activities is a major difference between the two approaches (Carroll 1996; Bekker and Long 2000; Sanders 2002; Kujala 2003).

Participatory design started in the Scandinavian countries in the 1970s for sociopolitical reasons (Ehn 1992; Floyd et al. 1989). Since that time, participatory design process has evolved away from politics and has turned into a point of interest for research. Design researchers and company designers have conducted participatory 
studies in many fields (e.g. interaction systems, management, services development, computer-supported cooperative work, physical ergonomics, etc.).

Several ideas support this shift towards a broader involvement of users. First, Carroll and Rosson (2007) stated the 'moral' aspect of participatory design, i.e. the fact that the user has a right to be involved in decision-making. Second, the 'pragmatic' aspect of participatory design relies on the fact that users' experience and knowledge can offer insights for concepts design (Carroll and Rosson 2007). Users are considered to be subject-matter experts who use the product in their everyday lives and have something to offer if designers offer them the right tools to express themselves (Sanders 2002). Third, a goal of participatory design is to go beyond the user's explicit consultation in order to elicit the user's tacit knowledge (Spinuzzi 2005). Tacit knowledge is the implicit knowledge that users hold about various aspects of an activity, including the way they interact with the product and perform the activity. According to Sanders (2002), the transfer of users' tacit knowledge to a concept is made possible by the fact that the user is in a 'making' situation, with the help of adapted tools. This would offer an access to their implicit skills and experiences that would be inaccessible by watching them or listening to what they say (Sanders 2002). Spinuzzi (2005) suggested that this meeting between users' tacit knowledge and researchers' more abstract analytical knowledge is the key point that leads participatory design to more successful products.

The link between user involvement and system success represents a significant body of the information systems literature since the late 70s (Bachore and Zhou 2009; Cavaye 1995; He and King 2008; Hwang and Thorn 1999; Ives and Olsson 1981; Kujala 2003). Nevertheless, as mentioned previously, levels of user involvement are on a continuum from informative to participative (Damodaran 1996). Therefore, it is 
sometimes difficult to distinguish clearly the boundary between consultative and participative involvement. Moreover, Damodaran $(1996,363)$ reported that 'the term "user involvement" is sometimes used as a synonym for participatory design'. To present relevant findings reporting benefits of participative involvement, this review focuses on articles reporting early user involvement, user participation in concept design activities, and studies aiming to be participatory design.

The main benefits of user involvement are summarised in five key points by: (1) improved product quality due to better definition of user requirements, (2) avoidance of costly features that users do not need or use, (3) better acceptance, (4) greater understanding of users, and (5) increased participation in decision-making. First, the improvement of product quality is also reviewed by Bachore and Zhou (2009). Kujala (2003) reported positive the effects of user involvement on system success.

Furthermore, Baroudi et al. (1986) suggested that user involvement has some positive effects on product usage. On participatory design studies, Clement and Van den Besselaar (1993) described the well-functioning nature of the products designed from the user perspective and their endurance over time. The improvement of the user requirements' definition is also reviewed by Kujala (2003) and Bachore and Zhou (2009). Nielsen (1994) mentioned the time wasted on certain projects arguing about what users might want or like. Participatory design allows the direct delivery of users' needs and expectations. Nielsen $(1994,88)$ also stated that users can bring new questions or ideas that the development team have 'not even dreamed of asking'. Second, concerning economic considerations, Karat (1997) suggested that early identification of problems can reduce time and avoid costs related to late changes. Chatzoglou and Macaulay (1996) supported this idea by arguing that early user involvement can lead to a decreased number of iterations during the design process to 
fulfil requirements. Third, user acceptance benefits due to user involvement are also reported by Bachore and Zhou (2009) and Kujala (2003). In one of the first participatory design projects, called UTOPIA (1981), results showed better communication between designers and users and increased user acceptance. Other subjective advantages are reported such as increased trust and user satisfaction (Weng et) al. 2007), self-confidence (Clement and Van den Besselaar 1993), and personal relevance (Kujala 2003). Fourth, greater understanding of the user mainly relies on the elicitation of tacit knowledge and on a mutual understanding between designers and participants (Weng et al. 2007). Finally, the increased participation of users in decisionmaking can result in organisational impacts (Bachore and Zhou 2009).

In parallel to this work in information systems, physical ergonomic researchers conducted participatory studies (Vink et al. 1995; Nagamachi 1995; McNeese et al. 1995; Xie et al. 2015; Morag and Luria 2013; Dixon and Theberge 2011). Improvements are reported in terms of a reduction in physical stress, health problems and development time (Loisel et al. 2001; Sundin, Christmansson, and Larsson 2004; Van Eerd et al. 2010; Gyi, Sang, and Haslam 2013). Other authors added that participative approaches could encourage sustainability (Martin, Legg, and Brown 2013; Ryan and Wilson 2013).

\section{From consultative to participative user involvement: Perspectives for automotive HMI design}

As mentioned earlier, some limitations can be addressed to user-centred design and usability testing, it is therefore important to explore alternative development possibilities. Based on the benefits reported, participatory design could be beneficial for 
automotive HMI design. First, economic benefits could be expected due to the early involvement of users and the reduction in iterations needed. Moreover, the potential avoidance of costly features (Damodaran 1996) would be particularly interesting for companies wishing to develop cost-efficient HMI. For example, for a new gauge design; with a user-centred design process, the different concepts of gauges presented necessarily restrict drivers' alternatives; whereas with a participatory design process, drivers are completely free to choose another concept (e.g. only alerts indicating malfunctions). Second, a better understanding of drivers' needs could lead to a better match with market expectations. Drivers are experts, especially in the automotive field, and participatory design could allow designers to access their insights and innovative ideas. Third, increased participation in decision-making could be a beneficial from a marketing and brand image perspective. Furthermore, participatory design studies report an impact on product quality and user acceptance. These benefits might be translated for automotive HMI by an improvement in their cognitive ergonomic quality (improved usability, improved acceptance, and reduced distraction).

\subsection{Participative user involvement to increase HMI usability}

While interacting with an interface, drivers engage working memory resources. Sweller (1988) suggested that an effective material improves and facilitates learning by directing cognitive resources to acquisition of mental models. Mental models are defined as 'a rich and elaborate structure, reflecting the user's understanding of what the system contains, how it works, and why it works that way' (Carroll and Olson 1988, 51). In long-term memory, mental models are composed of organised elements, and it allows retrieval of sub-elements of information as a single element (Kalyuga, Chandler, and Sweller 1999). For example, for an automotive interface such as a climate control 
panel, the driver develops mental a model of the way to interact with each button and associates this with the effects on interior temperature. This model will serve as reference path for the driver to interpret and predict his future interactions (LoupEscande, Burkhardt, and Richir 2013). Mental models are dynamic, contribute to user expertise, and are part of tacit knowledge. When a mental model is acquired, interaction is automated, and the number of cognitive resources needed to perform this interaction is reduced. For example, if a map is presented on a GPS, drivers' spatial representations based on their previous interactions with a map have to be considered. If the drivers' preferred orientation of the map is met, visual search and information processing efficiency will increase. The fact that part of the user's knowledge has become tacit through automation represents one of the difficulties of involving users and understanding their requirements (Sanders 2002).

For automotive HMI design, it would be a great advantage to have access to those implicit constructs. With a user-centred design process, tacit knowledge is addressed by evaluating the degree of match between the designers' conceptual model of the interface and the users mental models during usability tests (Norman 1993; Nielsen 2010). The focus is primarily on what users do and use and on what people say and think (Sanders 2002). With a participatory design, drivers are making concepts. This allows the consideration of skills and past experiences as resources in the design process, which is not possible by just listening or watching (Sanders 2002). Prototyping concepts with 'make tools' - so called by Sanders (2002) - give an access to different levels of driver's needs (i.e. explicit, tacit, latent) (Loup-Escande, Burkhardt, and Richir 2013). The projective dimension could encourage idea generation, and the visual dimension could help to reveal latent needs through a possible bottom-up effect. The ideas generated would be experience-based rather than only object-based. Drivers' 
mental models used as resources in the concept design stage could thus lead to better efficiency, learnability, memorability, a lower error rate and therefore increased HMI usability.

\subsection{Participative user involvement to decrease HMI distraction}

According to the National Highway Traffic Safety Administration (NHTSA 2012), 16\% of all road accidents are associated with a lack of driver's attention. Research syntheses conclude that priority should be given to minimising visual-manual interaction (NHTSA 2012). A single off-road glance (or eye closure) overlapping with a time critical event can lead to safety issues (Victor and Dozza 2011). A major part of the distraction associated with interacting with in-vehicle interfaces interaction also arises. The degree to which drivers' attention is diverted away from the primary driving task while using an in-vehicle HMI is determined in part by the design and operation of the device. For example, too much information presented through the wrong layout or information that is difficult to understand can increase workload and cause hazardous situations.

To minimise interference with driving, a consultative involvement relies on HMI guidelines and measures of distraction. The key recent NHTSA distraction guideline (NHTSA 2012) contains design recommendations and acceptance thresholds with the aim of minimising visual-manual distraction. Those measures are necessary even if a participatory design approach is applied. However, as mentioned above, user involvement during concept design could increase HMI usability and this could imply a decrease in distraction during HMI use. Indeed, a consideration of the information that the driver needs and the preferred layout associated could favour a low-clutter design resulting in increased visual search efficiency. Moreover, a better match with drivers' existing mental models could automate interaction and decrease the cognitive resources 
required to perform a task. By improving usability, a participative involvement in the design process could consequently decrease HMI distraction and lead to better compatibility with the driving task. The impact of participatory design on distraction would thus not be direct, but the result of a usability improvement.

\subsection{Participative user involvement to increase HMI acceptance}

Human-machine interface acceptance is crucial because accepted devices are more likely to be used by drivers. For example, a driver assistance system can be disabled if its HMI is annoying. Van Der Laan et al. stressed this point by stating that 'it is unproductive to invest effort in designing and building an intelligent co-driver if the system is never switched on, or even disabled' $(1997,1)$.

Since acceptance is individual, it can only be based on each driver's attitudes, expectations, experiences, and subjective evaluation (Schade and Baum 2007). User acceptance is also affected by the degree of match between the user's initial mental model of the system andits current use (Beggiato and Krems 2013). If the interfaces do not fit the drivers' mental models and expectations, they may lead to misuse, potentially hazardous situations, and rejection of the system (Maltz and Shinar 2004). Increased usability should thus improve driver acceptance. Likewise, new challenges for HMI designers are more linked to commercial aspects such as joy, aesthetics, HMI appeal, or pleasure of use (Nolimo Solman 2002). With consultative involvement, those subjective aspects are addressed with questionnaires during the HMI assessment. Participatory design benefits (i.e. satisfaction, product success, personal relevance, perceived ownership, intention to use) are directly linked to user acceptance (Weng et al. 2007;

Clement and Van den Besselaar 1993; Kujala 2003). Drivers' participative involvement 
in concept design could lead to a prior consideration of those subjective aspects and have a direct influence on drivers' willingness to use and subjective experience.

\section{Limitations inherent in a participative user involvement}

The participative user involvement embraced by participatory design seems a promising alternative to user-centred design and could enrich the debate for HMI researchers and practitioners. Nevertheless, some limitations have to be addressed to ensure a global view. Three main limitations are identified from the literature.

First, a lack of formalised methodology has been described by many authors. A broad range of practices is deployed (Pilemalm and Timpka 2008; Spinuzzi 2005; Haines et al. 2002). To overcome this limitation, Spinuzzi (2005) stated a clear methodology for participatory design. Moreover, another reproach is that the level of involvement during participative projects is often only assessed by surveys (Ives and Olsson 1981). Notwithstanding, some articles responded to those limitations: the definition of user involvement has been clarified (Barki and Hartwick 1989) and measures to qualify user involvement have been proposed (Barki and Hartwick 1989; Torkzadeh and Doll 1994).

Second, the benefits reviewed have been contested in terms of validity. The main criticisms concern the lack of rigour with standardised, reliable, and validated measures that could facilitate comparison of studies on system success, system use, and user satisfaction (Ives and Olsson 1981; Cavaye 1995). Moreover, the main reviews report a qualitative evaluation of the participatory project process and lack significant objective measures on the outcome quality. Clement and Van den Besselaar (1993) added that there is little data on the long-term effects of this type of approach. 
Furthermore, Hawk and Dos Santos (1991) called into question the economic benefits by pointing out that user involvement is costly in terms of time and effort, and this might be even truer for participatory design (designers' training in this process, expensive prototypes). More recently, Spinuzzi (2005) proposed three criteria to assess the participatory design process involving industrial workers: quality of life for workers (i.e. improving workers' quality of life both in terms of organisational empowerment and ease of performing their given task); collaborative development (i.e. representative users or average users have to be fully involved, with a determination of a common language and common aims); and iterative process (i.e. continual participation of workers during several stages ensuring a sustained reflection). To transfer this idea to an HMI participatory design process, the criteria would be: improvement of quality (i.e. the result of the participatory design study should make interaction easier for users); collaborative development (i.e. users' concerns have to be addressed in the resulting HMI concepts and must include verification and regular group interaction); and iterative process (i.e. involvement of users repeatedly and co-development at different stages, and ensuring the appearance of the HMI concept prototype does not turn participants' attention to minor details, to ensure sustained reflection).

Last but not least, the ability of users to add value in the concept design phase will be discussed. Indeed, drivers are not HMI professional designers and could experience difficulties in considering all aspects and requirements (industrial engineering, cognitive ergonomics, technical possibilities, project-lead times, brand image, etc.). Drivers could tend to focus on a single interaction element and not adopt a holistic vision. Moreover, Scariot, Heemann, and Padovani (2012) highlighted the potential for social desirability bias, i.e. users tend to direct answers to what they believe the researcher wants to hear or what is more socially accepted. Therefore, 
drivers could have difficulty identifying what they want until they see it. Henry Ford's famous quote reflects this point: 'If I had asked people what they wanted, they would have said faster horses' (cited in Chandler and Van Slee 2014, 35). Those issues emphasise the need to have a close collaboration with HMI designers, suitable interactive prototyping tools, and a rigorous methodology.

Obviously, the perspectives proposed in this article for automotive HMI design are not applicable for all types of projects. The form of user involvement to adopt depends on the available features, the number of usability risks, the gap between designers and users, and the level of tacit knowledge involved in the interaction. The conception of an entire dashboard can take several years for HMLdesigners. The design process is therefore very important to ensure the right direction and avoid costs associated with a step backwards. Determining the moment, the type, and the level of driver involvement are important aspects that should receive adequate research attention.

\section{Conclusion}

This review presents current automotive HMI design challenges and requirements in terms of HMI quality (i.e. usability, distraction, and acceptance). The benefits of participatory design have been reviewed and linked to HMI cognitive ergonomic preoccupations. In addition to economic and marketing opportunities, two key aspects have been pointed out. First, accessing drivers' tacit knowledge through active involvement during concept design could lead to an optimisation of HMI in terms of usability and minimise distraction. Second, the consideration of drivers' mental models and preferences from the concept design stage may also improve drivers' HMI 
acceptance.

However, it would be important to report participatory design benefits from a relative point of view. Indeed, the lack of comparative studies between the different levels of user involvement does not allow gauging the gap in terms of quality of outcomes. Further challenges could be to compare consultative and participative involvement with rigorous methodologies and measurements on the same automotive HMI design case. 


\section{References}

Abras, C., D. Maloney-Krichmar, and J. Preece. 2004. "User-Centered Design.” Bainbridge, W. Encyclopedia of Human-Computer Interaction. Thousand Oaks: Sage Publications 37 (4): 445-456.

Adell, E. 2010. “Acceptance of Driver Support Systems.” Proceedings of the European Conference on Human Centred Design for Intelligent Transport Systems, Berlin, Germany.

Baber, C. 2005. "Evaluation in Human-Computer Interaction." In Evaluation of Human Work, edited by J. R. Wilson and N. Corlett, 357-387. London: Taylor \& Francis.

Bachore, Z., and L. Zhou. 2009. "A Critical Review of the Role of User Participation in IS Success." Proceedings of the Fifteenth Americas Conference on Information Systems.

Barki, H., and J. Hartwick. 1989. "Rethinking the Concept of User Involvement." MIS Quarterly 13 (1): 53-63.

Baroudi, J. J., M.H. Olson, and B. Ives. 1986. "An Empirical Study of the Impact of User Involvement on System Usage and Information Satisfaction." Communications of the ACM 29 (3): 232-38.

Bastien, J.M.C., and D.L. Scapin. 1992. "A Validation of Ergonomic Criteria for the Evaluation of Human-Computer Interfaces.” International Journal of HumanComputer Interaction 4 (2): 183-96.

Beggiato, M., and J. F. Krems. 2013. "The evolution of mental model, trust and acceptance of adaptive cruise control in relation to initial information." Transportation Research Part F: Traffic Psychology and Behaviour 18:47-57.

Bekker, M., and J. Long. 2000. "User Involvement in the Design of Human-Computer Interactions:Some Similarities and Differences between Design Approaches." In People and Computers XIV-Usability or Else: Proceedings of HCI 2000, 135147. Springer.

Beyer, H., and K. Holtzblatt. 1999. "Contextual design.” Interactions 6(1): 32-42.

Bilal, D. 2013. "Children Design Their Interfaces for Web Search Engines: A Participatory Approach." In Proceedings of the Canadian Association for Information Science, 204-214. 
Blomberg, J., J. Giacomi, A. Mosher, and P. Swenton-Wall. 1993. "Ethnographic field methods and their relation to design." Participatory Design: Principles and Practices 123-155.

Brown, M., R. Houghton, S. Sharples, and J. Morley. 2015. "The Attribution of Success When Using Navigation Aids.” Ergonomics 58 (3): 426-433.

Bruno, F., and M. Muzzupappa. 2010. "Product Interface Design: A Participatory Approach Based on Virtual Reality." International Journal of Human-Computer Studies 68 (5): 254-269.

Campbell, J.L., C.M. Richard, J.L. Brown, and M.McCallum. 2007. "Crash Warning System Interfaces: Human Factors Insight and Lessons Learned." US Department of Transportation, National Highway Traffic Safety Administration, no. HS-810 697.

Caplan, S. 1990. "Using Focus Group Methodology for Ergonomic Design." Ergonomics 33 (5): 527-533.

Carmel, E., R. D. Whitaker, and J. F. George. 1993. "PD and Joint Application Design: A Transatlantic Comparison." Communications of the ACM 36(4):40-48.

Carroll, J.M., and J.R. Olson. 1988. "Mental Models in Human-Computer Interaction: Research Issues about What the User of Software Knows." In The Handbook of Human-Computer Interaction, edited by M. Helander, 45-65. Amsterdam: North Holland.

Carroll, J.M., and M.B. Rosson. 2007. "Participatory Design in Community Informatics." Design Studies 28 (3): 243-61.

Cavaye, A.L.M. 1995. "User Participation in System Development Revisited." Information \& Management 28 (5): 311-323.

Chandler, C, and A. Van Slee. 2013. Adventures in Experience Design. Berkeley: New Riders.

Chapon, A., C. Gabaude, and A. Fort. 2006. Défauts d'attention et conduite automobile: état de l'art et nouvelles orientations pour la recherche dans les transports. Paris: Synthèse INRETS.

Chatzoglou, P.D., and L.A. Macaulay. 1996. "Requirements Capture and Analysis: A Survey of Current Practice." Requirements Engineering 1 (2): 75-87.

Clement, A., and P. Van den Besselaar. 1993. “A Retrospective Look at PD Projects." Communications of the ACM 36 (6): 29-37. 
Commission of the European Communities. 2005. European Statement of Principles on the Design of Human Machine Interaction (ESoP 2005). Brussels: Commission of the European Communities.

Constantine, L.L, and L.A.D. Lockwood. 1999. Software for Use: A Practical Guide to the Models and Methods of Usage-Centered Design. Boston: Addison-Wesley.

Damodaran, L. 1996. "User Involvement in the Systems Design Process - a Practical Guide for Users." Behaviour \& Information Technology 15 (6): 363-377.

Davis, F. D., R. P. Bagozzi, and P. R. Warshaw. 1989. "User Acceptance of Computer Technology: A Comparison of Two Theoretical Models." Management Science 35: 982-1003.

Dixon, S. M., and N. Theberge. 2011. "Contextual Factors Affecting Task Distribution in Two Participatory Ergonomic Interventions: A Qualitative Study." Ergonomics 54(11): 1005-1016.

Dumas, J.S, and J. Redish. 1999. A Practical Guide to Usability Testing. Oregon: Intellect Books.

Eason, K.D. 1995. “User-Centred Design: For Users or by Users?” Ergonomics 38 (8): $1667-1673$.

Ehn, P. 1992. "Scandinavian Design: On Participation and Skill.” In Usability: Turning technologies into tools, 96-132. New York: Oxford University Press.

Fishbein, M., and I. Ajzen. 1975. Belief, Attitude, Intention, and Behavior: An Introduction to Theory and Research. Boston: Addison-Wesley.

Floyd, C., W-M Meh1, F-M Reisin, G. Schmidt, and G. Wolf. 1989. "Out of Scandinavia: Alternative Approaches to Software Design and System Development." Human-Computer Interaction 4 (4): 253-350.

Gould, J. D., and C. Lewis. 1985. "Designing for Usability: Key Principles and What Designers Think." Communications of the ACM 28 (3): 300-311.

Gyi, D., K. Sang, and C. Haslam. 2013. "Participatory Ergonomics: Co-Developing Interventions to Reduce the Risk of Musculoskeletal Symptoms in Business Drivers." Ergonomics 56 (1): 45-58.

Haines, P.H, J.R Wilson, P. Vink, and E. Koningsveld. 2002. "Validating a Framework for Participatory Ergonomics (the PEF)." Ergonomics 45 (4): 309-327.

Harvey, C., N.A. Stanton, C.A. Pickering, M. McDonald, and P. Zheng. 2011. "Context of Use as a Factor in Determining the Usability of in-Vehicle Devices." Theoretical Issues in Ergonomics Science 12 (4): 318-338. 
Hawk, S.R., and B.L. Dos Santos. 1991. "Successful System Development: The Effect of Situational Factors on Alternate User Roles." IEEE Transactions on Engineering Management 38 (4): 316-327.

He, J., and W. R. King. 2008. "The Role of User Participation in Information Systems Development: Implications from a Meta-Analysis.” Journal of Management Information Systems 25 (1): 301-331.

Herstatt, C., and E. Hippel. 1992. "From Experience: Developing New Product Concepts Via the Lead User Method: A Case Study in a "Low-Tech" Field." Journal of Product Innovation Management 9(3):213-221.

Hwang, M. I, and R. G Thorn. 1999. "The Effect of User Engagement on System Success: A Meta-Analytical Integration of Research Findings." Information \& Management 35 (4): 229-236.

International Organization for Standardization. 1998. ISO9241-11 Ergonomic Requirements for Office Work with Visual Display Terminals (VDTs) - Part 11 : Guidance on Usability. London: International Organization for Standardization. International Organization for Standardization. 1999. ISO 13407, Human-Centred Design Processes for Interactive Systems. London: International Organization for Standardization.

Ives, B., and M. Olsson. 1981. User Involvement in Information Systems: A Critical Review of the Empirical Literature. New York: New York University.

Japan Automobile Manufacturers Association. 2004. Guideline for in-Vehicle Display Systems, Version 3.0. Tokyo: JAMA.

Kalyuga, S., P. Chandler, and J. Sweller. 1999. "Managing Split-Attention and Redundancy in Multimedia Instruction.” Applied Cognitive Psychology 13 (4): $351-371$.

Karat. J. 1997. "Evolving the Scope of User-Centered Design." Communications of the ACM 40 (7): 33-38.

Kaulio, M.A. 1998. "Customer, Consumer and User Involvement in Product Development : A Framework and a Review of Selected Methods." Total Quality Management 9 (1): 141-49.

Kirwan, B., and L.K. Ainsworth. 1992. A Guide to Task Analysis: The Task Analysis Working Group. London: Taylor \& Francis.

Kujala, S. 2003. "User Involvement : A Review of the Benefits and Challenges." Behaviour \& Information Technology 22 (1): 1-16. 
Larsson, P., and M. Niemand,. 2015. "Using Sound to Reduce Visual Distraction from In-vehicle Human-Machine Interfaces.” Traffic Injury Prevention 16:S25-S30. Lee, J.H. 2008. "User-Designer Collaboration during the Early Stage of the Product Development Process.” PhD diss., Queensland University of Technology.

Leplat, J. 1981. "Task analysis and activity analysis in situations of field diagnosis." In Human detection and diagnosis of system failures., edited by Jens Rassumussen, 287-300. New York: Plenum.

Leonard, D., and J. F. Rayport. 1997. "Spark innovation through empathic design?" Harvard Business Review 75:102-115.

Loisel, P., L. Gosselin, P. Durand, J. Lemaire, S. Poitras, and L. Abenhaim.2001. "Implementation of a Participatory Ergonomics Program in the Rehabilitation of Workers Suffering from Subacute Back Pain.” Applied Ergonomics 32 (1): 5360.

Loup-Escande, E., J-M. Burkhardt, and S. Richir. 2013. “Anticiper et évaluer l'utilité dans la conception ergonomique des technologies émergentes: une revue." Le Travail Humain 76 (1): 27-55.

Ma, R., and D.B. Kaber, D. B. 2007. "Situation awareness and driving performance in a simulated navigation task." Ergonomics 50(8): 1351-1364.

Macaulay, L.A. 1996. Requirements Engineering. Berlin: Springer-Verlag.

Maltz, M., and D. Shinar. 2007. "Imperfect in-vehicle collision avoidance warning systems can aid distracted drivers." Transportation Research Part F: Traffic Psychology and Behaviour 10(4):345-357.

Marcus, A. 2004. "Vehicle User Interfaces: The next Revolution.” Interactions 11(1): $40-47$.

Martin, K., S. Legg, and C. Brown. 2013. "Designing for Sustainability: Ergonomics Carpe Diem." Ergonomics 56 (3): 365-388.

Morag, I., and G. Luria. 2013. "A Framework for Performing Workplace Hazard and Risk Analysis: A Participative Ergonomics Approach.” Ergonomics 56 (7): 1086-1100.

McNeese, M.D., S. Zaff, M. Citera, C.E. Brown, and R. Whitaker. 1995. “AKADAM : Eliciting User Knowledge to Support Participatory Ergonomics.” International Journal of Industrial Ergonomics 15 (5): 345-363.

Moraes, A., and S. Padovani. 1998. "Participatory Evaluation and Design of a Subway Train Cabin.” Participatory Design Conference, 211-217. 
Nagamachi, M. 1995. "Requisites and Practices of Participatory Ergonomics." International Journal of Industrial Ergonomics 15 (5): 371-377.

Najm, W.G., M.D. Stearns, H. Howarth, J. Koopmann, and J. Hitz. 2006. Evaluation of an Automotive Rear-End Collision Avoidance System. No. DOT-VNTSCNHTSA-06-01. Washington: National Highway Traffic Safety Administration. National Highway Traffic Safety Administration. 2012. Visual-Manual NHTSA Driver Distraction Guidelines For In-Vehicle Electronic Devices. Washington: National Highway Traffic Safety Administration.

Navarro, J., F. Mars, and J.M. Hoc. 2007. "Lateral Control Assistance for Car Drivers: A Comparison of Motor Priming and Warning Systems." Human Factors 49(5):950-960.

Nielsen, J. 1990. "Paper versus Computer Implementations as Mock up Scenarios for Heuristic Evaluation." In Proceedings of the IFIP Tc13 Third Interational Conference on Human-Computer Interaction, 315-20. Amsterdam: NorthHolland.

Nielsen, J. 1994. Usability Engineering. Amsterdam: Elsevier Science Publishers.

Nielsen, J. 2008. “Bridging the Designer-User Gap.” Nielsen Norman Group, Accessed April 15, 2015. http://www.nngroup.com/articles/bridging-the-designer-usergap/

Nielsen, J. 2010. “Mental Models.” Nielsen Norman Group, Accessed January 4, 2016. https://www.nngroup.com/articles/mental-models/

Nielsen, J. 2012. "Usability 101: Introduction to Usability." Nielsen Norman Group, Accessed January 4, 2016. https://www.nngroup.com/articles/usability-101introduction-to-usability/

Norman, D.A. 1993. "Some observations on mental models." Mental Models 7(112):714.

Olsen, G. 2004. "Persona Creation and Usage Toolkit." Interaction by Design, Accessed April 15, 2015. http://www.interactionbydesign.com/presentations/olsen_ persona_toolkit.pdf

Pettitt, M., G.E. Burnett, and A. Stevens. 2005. "Defining Driver Distraction." Proceedings of the 12th ITS World Congress, San Francisco, November 6-10.

Pilemalm, S., and T. Timpka. 2008. "Third Generation Participatory Design in Health Informatics-Making User Participation Applicable to Large-Scale Information System Projects.” Journal of Biomedical Informatics 41 (2): 327-339. 
Poulson, D., M. Ashby, and S. Richardson. 1996. USERfit: A Practical Handbook on User-Centred Design for rehabilitation for Assistive Technology.

Loughborough: HUSAT Research Institute for the European Commission.

Preece, J., Y. Rogers, and H. Sharp. 2011. Interaction Design: Beyond Human-

Computer Interaction. New York: John Wiley \& Sons.

Preece, J., Y. Rogers, H. Sharp, D. B., S. Holland, and T. Carey. 1994. HumanComputer Interaction. Boston: Addison-Wesley.

Reimer, B., B. Mehler, J. Dobres, J. F. Coughlin, S. Matteson, D. Gould, N. Chahine, and V. Levantovsky. 2014. "Assessing the Impact of Typeface Design in a TextRich Automotive User Interface." Ergonomics 57(11): 1643-1658.

Ryan, B., and J.R. Wilson. 2013. "Ergonomics in the Development and Implementation of Organisational Strategy for Sustainability." Ergonomics 56(3): 541-555.

Sanders, E.B.N. 2002. "From User-Centered to Participatory Design Approaches." In Design and the Social Sciences. London: Taylor \& Francis.

Scariot, C.A, A. Heemann, and S. Padovani. 2012. "Understanding the CollaborativeParticipatory Design.” Work: A Journal of Prevention, Assessment and Rehabilitation 41: 2701-2705.

Schade, J., and M. Baum. 2007. "Reactance or Acceptance? Reactions towards the Introduction of Road Pricing." Transportation Research Part A: Policy and Practice 41 (1): 41-48.

Shackel, B. 1986. "Ergonomics in Design for Usability." In Proceedings of the Second Conference of the British Computer Society, Human Computer Interaction Specialist Group on People and Computers: Designing for Usability, 44-64. Cambridge: Cambridge University Press.

Shneiderman, B, 1992. Designing the User Interface: Strategies for Effective HumanComputer Interaction. Boston: Addison-Wesley.

Solman, K. N. 2002. "Analysis of Interaction Quality in Human - Machine Systems : Applications for Forklifts.” Applied Ergonomics 33 (2): 155-166.

Spinuzzi, C. 2005. "The Methodology of Participatory Design.” Technical Communication 52 (2): 163-174.

Stanton, N.A., and C. Baber. 1992. “Usability and EC Directive 90/270.” Displays 13 (3): 151-160. 
Stanton, N. A., C. Harvey, K.L. Plant, and L. Bolton. 2013. "To twist, roll, stroke or poke? A study of input devices for menu navigation in the cockpit." Ergonomics 56(4): 590-611.

Stevens, A., A. Quimby, A. Board, T. Kersloot, and P. Burns. 2002. Design Guidelines for Safety of in-Vehicle Information Systems (Project Report PA3721/01). Workingham: Transport Local Government.

Sundin, A., M. Christmansson, and M. Larsson. 2004. "A Different Perspective in Participatory Ergonomics in Product Development Improves Assembly Work in the Automotive Industry." International Journal of Industrial Ergonomics 33 (1): $1-14$.

Sweller, J. 1988. "Cognitive Load during Problem Solving: Effects on Learning." Cognitive Science 12 (2): 257-285.

Torkzadeh, G., and W.J. Doll. 1994. "The Test-Retest Reliability of User Involvement Instruments." Information and Management 26(1): 21-31.

Van Der Laan, J.D., A. Heino, and D. De Waard. 1997. “A Simple Procedure for the Assessment of Acceptance of Advanced Transport Telematics." Transportation Research Part C: Emerging Technologies 5 (1): 1-10.

Van Eerd, D., D. Cole, E. Irvin, Q. Mahood, K. Keown, N. Theberge, J. Village, M. St Vincent, and K. Cullen. 2010. "Process and Implementation of Participatory Ergonomic Interventions: A Systematic Review.” Ergonomics 53 (10): 11531166.

Venkatesh, V., M. G. Morris, G. B. Davis, and F. D. Davis. 2003. "User Acceptance of Information Technology: Toward a Unified View.” MIS Quarterly 27 (3): 425478.

Victor, T., and M. Dozza. 2011. "Timing Matters: Visual Behaviour and Crash Risk in the 100-Car Online Data." 2nd International Conference on Driver Distraction and Inattention, Gothenburg, Sweden.

Vink, P., M. Peeters, R. W. M. Griindemann, P. G. W. Smulders, M. A. J. Kompier, and J. Dul. 1995. “A Participatory Ergonomics Approach to Reduce Mental and Physical Workload.” International Journal of Industrial Ergonomics 15 (5): 389-396.

Weng, C., D.W. McDonald, D. Sparks, J. McCoy, and J.H. Gennari. 2007. "Participatory Design of a Collaborative Clinical Trial Protocol Writing System.” International Journal of Medical Informatics 76(1): 245-251. 
Xie, A., P. Carayon, E. D. Cox, R. Cartmill, Y. Li, T. B. Wetterneck, and M. M. Kelly. 2015. "Application of Participatory Ergonomics to the Redesign of the FamilyCentred Rounds Process." Ergonomics. Advance online publication.

Young, M.S., K. A. Brookhuis, C. D. Wickens, and P. A. Hancock. 2015. "State of Science: Mental Workload in Ergonomics.” Ergonomics 58(1): 1-17.

Young, K., M. Regan, and M. Hammer. 2007. Driver Distraction : A Review of the Literature. Melbourne: Monash University Accident Research Centre.

Young, K.., M. Regan, T.J. Triggs, N. Tomasevic, K. Stephan, and E. Mitsopoulos. 2007. "Impact on car driving performance of a following distance warning system: findings from the Australian Transport Accident Commission SafeCar Project." Journal of Intelligent Transportation Systems 11(3): $121<131$. 


\section{Table}

Table 1. A framework to qualify automotive HMI cognitive ergonomic quality

\begin{tabular}{|c|c|c|}
\hline HMI quality criterion & Attribute & Description \\
\hline \multirow{5}{*}{$\begin{array}{l}\text { Usability } \\
\text { (according to Nielsen } \\
\text { 1994) }\end{array}$} & Learnability & $\begin{array}{l}\text { The HMI enables the user to learn how to use it at } \\
\text { first encounter. }\end{array}$ \\
\hline & Efficiency & $\begin{array}{l}\text { The HMI enables the user to complete the correct } \\
\text { task without requiring unnecessary resources. }\end{array}$ \\
\hline & Memorability & $\begin{array}{l}\text { The HMI enables the user to remember how to } \\
\text { use it after a period of not using it. }\end{array}$ \\
\hline & Errors & $\begin{array}{l}\text { The use of the HMI does not imply errors and } \\
\text { enables an easy recovery from an error. }\end{array}$ \\
\hline & Satisfaction & The use of the HMI is pleasant. \\
\hline \multirow{2}{*}{$\begin{array}{l}\text { Distraction } \\
\text { (according to Chapon, } \\
\text { Gabaude, and Fort 2006) }\end{array}$} & Physical & $\begin{array}{l}\text { The HMI optimises required movement to } \\
\text { perform a task. }\end{array}$ \\
\hline & Cognitive & $\begin{array}{l}\text { The HMI reduces required cognitive workload to } \\
\text { perform a task. }\end{array}$ \\
\hline \multirow{3}{*}{$\begin{array}{l}\text { Driver acceptance } \\
\text { (according to Davis, } \\
\text { Bagozzi, and Warshaw } \\
\text { 1989) }\end{array}$} & $\begin{array}{l}\text { Perceived } \\
\text { usefulness }\end{array}$ & $\begin{array}{l}\text { The degree to which a person believes that using } \\
\text { the HMI is useful and enhances his performance. }\end{array}$ \\
\hline & $\begin{array}{l}\text { Perceived ease } \\
\text { of use }\end{array}$ & $\begin{array}{l}\text { The degree to which a person believes that using } \\
\text { the HMI is free from effort. }\end{array}$ \\
\hline & & $\begin{array}{l}\text { User's feelings about performing the task with the } \\
\text { HMI. }\end{array}$ \\
\hline
\end{tabular}




\section{Figure caption}

Figure 1. A correspondence between the different levels of user involvement and the phases of the human-centred design process. Figure adapted from Kaulio (1998)

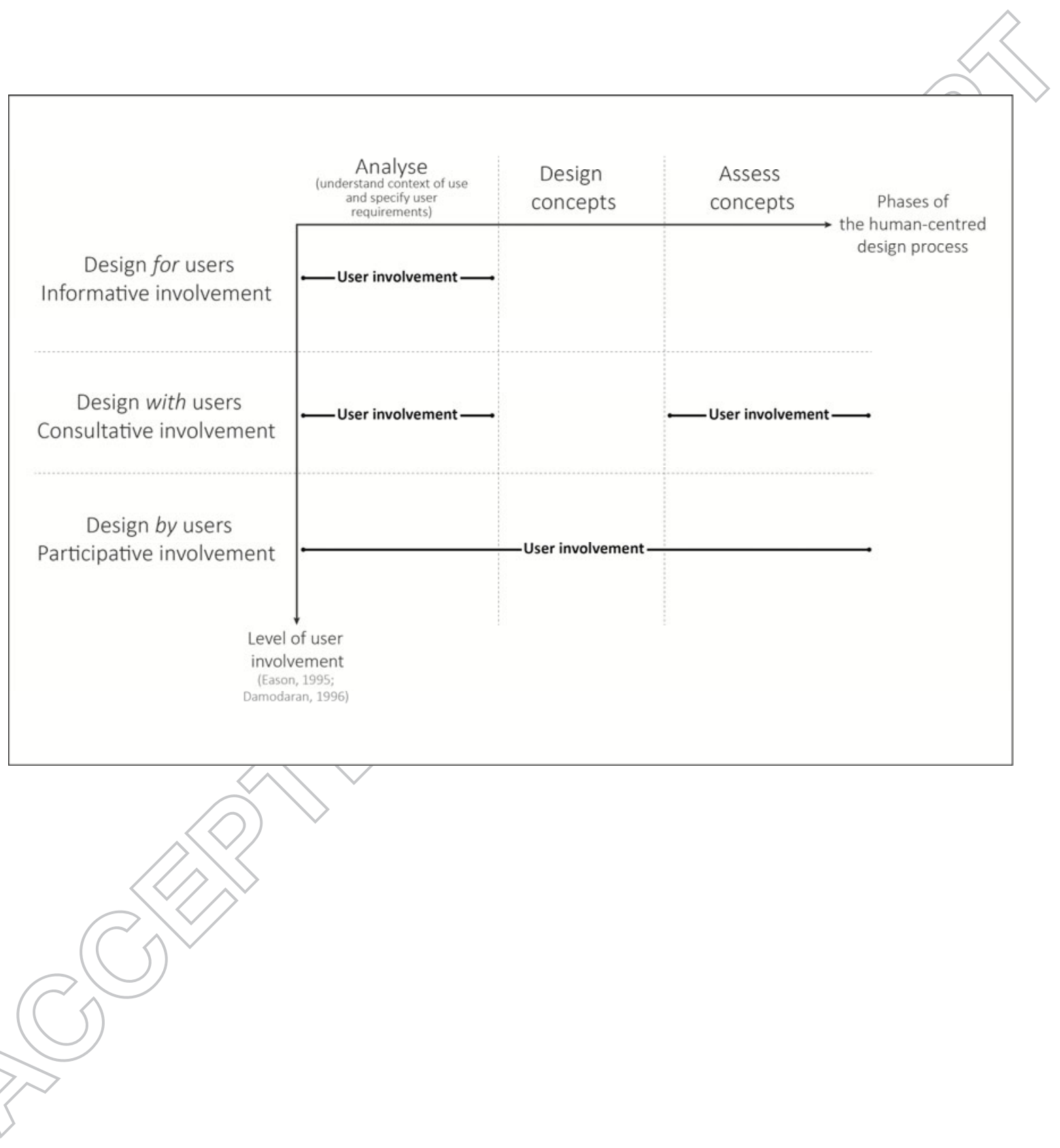

